УДК 930.1:321.6

КРИТИЧЕСКИЙ ДИСКУРС ТОТАЛИТАРИЗМА В ЗАРУБЕЖНОЙ ИСТОРИОГРАФИИ 1960-Х ГГ. Елена В. Мороз ${ }^{1, @ ~}$

${ }^{1}$ Кемеровский институт (филиал) Российского экономического университета им. Г. В. Плеханова, 650992,

Россия, г. Кемерово, пр. Кузнеикий, 39

@morozkem@yandex.ru

Поступила в редакичию 10.10.2017. Принята к печати 28.11.2017.

Ключевые слова: тоталитаризм, историография, диктатура, фашизм, коммунизм, критика.
Аннотация: Цель статьи - проанализировать причины, основное содержание критического дискурса о тоталитаризме в зарубежной историографии 1960-х гг. Анализ осуществляется с помощью основополагающих методологических принципов историографического исследования: системного подхода, историзма и научной объективности. Основное внимание уделяется работам известных зарубежных исследователей этого феномена, таких как Х. Арендт, П. Сорокин, К. Фридрих, 3. Бжезинский, Р. Миллс, А. Улам. Через раскрытие содержания этих работ выделяются основные методологические проблемы критического дискурса. Критике была подвержена тоталитарная модель за структурное и внешнее однообразие, незначительное внимание к различиям тоталитарных режимов. Ревизионизм в зарубежной историографии $60-$ х гг. способствовал изучению советского общества на базе социологической методологии, выделив его высокую социальную мобильность. В рамках критической дискуссии были выделены различия между коммунистическими и фашистскими системами, особенности отдельных коммунистических режимов. Однако представителям критического направления так и не удалось создать цельную теорию, по сравнению с адептами тоталитаризма. Критический дискурс тоталитаризма в 1960-е гг. способствовал формированию модернизированной концепции феномена. В заключении статьи делаются основные выводы дискуссии. Содержание и результаты данной статьи могут быть использованы в лекционных курсах по зарубежной историографии.

Для цитирования: Мороз Е. В. Критический дискурс тоталитаризма в зарубежной историографии 1960-х гг. // Вестник Кемеровского государственного университета. 2018. № 1. C. 66-73. DOI:10.21603/2078-8975-2018-1-66-73.

Данная статья является продолжением многолетних исследований американской историографии тоталитаризма [1].

Актуальность продолжения исследования обусловлена тем, что активная дискуссия о тоталитаризме конца 1980-х - 1990-х гг. прекратилась, а в последнее десятилетие вообще пропал интерес к проблеме тоталитаризма в отечественной науке. Появляются лишь небольшие статьи, в которых поверхностно применяется модель тоталитаризма к новым государствам [2] или дается пересказ существующих теоретических работ классиков теории [3]. Вместе с тем с приходом в историческую науку нового поколения, то есть каждые 15-20 лет, необходимо обновлять историографические концепции. Думается, что эвристический потенциал феномена тоталитаризма до сих пор не исчерпан как в научном, так и политическом смысле. Так, адепты тоталитаризма до сих пор используют данный методологический конструкт для формирования сознания политической элиты в США и странах Европейского Союза. А элиты этих стран, в свою очередь, очень активно последнее время применяют термин «тоталитаризм» для оценки политических режимов не только в Сирии и Ливии, но и все чаще при характеристике политической ситуации в нашей стране. Поэтому очень важно изучать критику тоталитаризма непосредственно американских и западноевропейских исследователей о борьбе с тоталитарным подходом в России.

В сравнении с предыдущими работами [4] более глубоко дается методологический анализ новых историографических источников не только американских, но и французских, немецких исследователей.

К 1960-м гг. концепция тоталитаризма, зародившаяся в 20-е гг. прошлого века [5], стала подвергаться критике в зарубежной историографии. В эти годы термин «свободный мир», так часто используемый в качестве антонима тоталитаризму, становился все более бессодержательным. Все виды представительных правительств считались частью свободного мира просто потому, что они были антикоммунистическими, среди них наиболее известными были сменявшие друг друга режимы в Южном Вьетнаме.

Зарубежные историки и политологи все более критически стали смотреть на теорию тоталитаризма, находясь под влиянием политической ситуации как в собственных странах, так и тех изменений, которые происходили в Советском Союзе. Парадокс заключался в том, что критике в эти годы подвергался даже «эталон демократии» - Соединенные Штаты. 
Был возрожден критиками старый аргумент о том, что СССР присутствует в Центральной Европе по соображениям безопасности, который задолго до этого был заменен представлением времен холодной войны (часто явно не выражаемым) в том, что советский тоталитаризм ведет Советский Союз к расширению своего влияния как в Европе, так и в Азии. Некоторые радикальные ученые даже стали утверждать, что создатели американской политики просто изобрели советскую угрозу как способ запугать общество, чтобы оно приняло гонку вооружений, реальной целью которых было поддержать крестовый поход для того, чтобы сделать весь мир безопасным для американского капитала.

Другим фактором, играющим роль в распространении критики понятия «тоталитаризм», которая усиливалась в течение 1960-х гг., было «возрождение» марксизма в качестве предпочтительной терминологии для выражения несогласия с ценностями буржуазного общества среди молодых европейских и американских интеллектуалов. Возрождаемый марксизм, по их мнению, - это «ранний марксизм», марксизм отчуждения, а не поздний марксизм «Капитала», который развился до институционализированного марксизма Второго, а затем Третьего Интернационала [6]. Но для марксистов или для мыслящих в марксистском русле интеллектуалов всегда было непросто усвоить тоталитарную модель. В рамках этой модели невозможны были традиционные отношения базиса и надстройки и прямо сравнивая коммунизм и фашизм, она могла быть чрезвычайно вредной для мировоззрения левых. Возрождение марксизма было также связано с распространением утопического образа мышления среди молодых американцев и европейцев. Духу бунтарского утопизма было суждено войти в решительное столкновение со сдержанным и прагматическим либерализмом более старых ученых.

Значительное влияние на изменение отношения к тоталитаризму в зарубежной историографии оказала эволюция советского политического режима после смерти Сталина и разоблачений Хрущевым «культа личности» [7].

Критический дискурс в 1960-е гг. был обусловлен необходимостью более детального изучения различных форм тоталитаризма. Критика была направлена на методологию формирования понятия «тоталитаризм», которое включает структурные признаки тоталитарного господства, ведущие при упрощённом подходе к абстрагированию от конкретных политико-социальных факторов отдельных режимов [8].

Критический дискурс оказал влияние даже на такие «классические» концепции тоталитаризма, как «тоталитарный синдром» 3. Бжезинского и К. Фридриха. Концепция тоталитаризма К. Фридриха и 3. Бжезинского эволюционирует через выделение «ранней» и «зрелой» стадий тоталитаризма и введение циклического понятия текущих «жестких» и «терпимых» фаз тоталитаризма [9, p. 275].

«Ранние» стадии и текущие «жесткие» фазы соответствуют первоначальному тоталитарному синдро- му, тогда как «зрелый» тоталитаризм и «терпимые» фазы характеризуются редактированной версией синдрома, которая включает психологический террор, децентрализацию, коллективное руководство, частичную литературную и художественную свободу, «социалистическую законность».

Хотя издание рассматривается как «частичная критика» понятия «тоталитаризм», оно содержит в себе доказательства убеждения К. Фридриха в том, что «в целом ... как теория, так и практика тоталитарной диктатуры стремятся подтвердить анализ, который мы предложили» $[9$, p. VII]. По мнению исследователей, «нет никаких оснований считать, что прежняя тоталитарная система вследствие своего внутреннего развития исчезла, хотя она, без сомнения, претерпела существенные изменения» $[9, \mathrm{p} .17]$.

В 1966 г. появляется новое издание одной из самых известных работ по тоталитаризму - книга X. Арендт «Истоки тоталитаризма» [10]. Определенная эволюция взглядов на феномен изложена в двадцатистраничном вводном очерке. Х. Арендт была готова признать, что смерть Сталина была решающим моментом, за которым последовал «не просто кризис преемника и временная «оттепель» в течение того периода, пока новый лидер не утвердит себя, но реальный процесс детоталитаризации, хотя так никогда и не ставший последовательным» [11, p. XXV].

$\mathrm{X}$. Арендт не пытается объяснить динамику советской детоталитаризации. Она приписывает значительное влияние на этот факт самой смерти Сталина, и в этом отношении оказывается солидарной с точкой зрения американского исследователя Р. Такера о решающей роли тоталитарного лидера. Возможно, по этой причине она верит, что Советский Союз «может впасть снова в тоталитаризм сегодня или завтра без государственного переворота» [10, p. IX].

Существенной эволюции концепция тоталитаризма X. Арендт не претерпела, она создала мир, в котором политические силы добра противостоят силам зла, и в котором, по мнению самой Х. Арендт, «сосуществование невозможно» [10, p. XII].

$\mathrm{B}$ отличие от Х. Арендт, известный французский политолог Р. Арон в книге «Демократия и тоталитаризм» (1965 г.) более осторожен в сравнении левого и правого вариантов тоталитаризма. Р. Арон видит не только черты сходства, но и различия: в социальных базах партий, в несовместимости идеологий. Он считает, что при сравнении двух режимов необходимо учитывать «два метода: история и идеология» [12]. Р. Арон полагает, что «советский режим порожден революционной волей, вдохновляемой гуманистическим идеалом» $[12$, с. 236$]$, а «гитлеровский режим возник из-за стремления возродить моральное единство Германии» [12, с. 240].

Работа Р. Арона под влиянием хрущевской «оттепели» далека от крайне жестких оценок советского режима. Более того, Р. Арон выделяет в истории советского режима в качестве тоталитарных лишь отдельные периоды. Этот новый методологический 
подход необходимо рассматривать в контексте критического дискурса 1960-х гг.

Постепенно в рамках критического дискурса о тоталитаризме в зарубежной историографии стали изучать новые объекты. Так, наш соотечественник П. Сорокин, вынужденный эмигрировать в 20-е гг. прошлого века из России, в 1960 г. публикует свое эссе «Взаимное сближение Соединенных Штатов и СССР к смешанному социокультурному типу», в котором он практически не различает капиталистический и коммунистический типы обществ, а предлагает новый «интегральный» [13, р. 143].

Известный американский социолог Р. Миллс еще более категоричен в своих оценках, назвав США как «консервативную страну без консервативной идеологии». В книге «Властвующая элита» Миллс пишет: «США прошли уже значительное расстояние по пути к политически «инертному обществу», а этот путь ведет к тоталитарному государству» [14, с. 416].

В 1960-е гг. интерес к советскому режиму возрастает. С введением системы академических обменов в 60-х гг. зарубежные преподаватели и выпускники вузов стали посещать Советский Союз. Время, проведенное в Советском Союзе, обычно оказывало разрушительное воздействие на левые, просоветские взгляды, вместе с тем подрывался взгляд и на тоталитарную модель. Государство в СССР, конечно, вмешивалось во все сферы жизни, но разница между этим вмешательством и кошмарными видениями книги «1984 год» выглядела значительной в глазах иностранцев [15]. Эти изменения создавали фон методологического развития исследований в советологии, а иногда выходили и на передний план [16, p. 131-132].

Пример тому - книга известного американского советолога из Российского исследовательского центра Гарвардского университета А. Улама «Новое лицо советского тоталитаризма», в которой анализируется советский режим в постсталинский период [17].

Под тоталитаризмом понимается система, включающая в себя режим и идеологию $[17$, р. 60$]$. В своей работе А. Улам придерживается распространенного в американской советологии мнения, что основателем советской тоталитарной идеологии является В. И. Ленин, идеи которого претворил на практике, создав тоталитарный режим, И. Сталин.

К тоталитарной модели А. Улам относит фашистский, национал-социалистический и советский режимы. При этом основным объектом исследования для А. Улама остается советский вариант. Повторяя точку зрения Х. Арендт, А. Улам считает террор и идеологию основными чертами советского тоталитарного режима.

А. Улам не ставит своей задачей построить модель советского тоталитаризма, поэтому он дает не структурный, а функциональный анализ системы. Существование и развитие советской тоталитарной системы объясняется состоянием существования перманентного врага, с которым необходимо бороться. Внешняя политика также рассматривается через идеологические установки на расширение тоталитарной системы.
В самом названии книги автор подчеркивает, что на момент написания книги, т. е. после смерти Сталина, советская система остается тоталитарной, но с новым лицом. Что же новое выделяет Улам? Это некоторые попытки профессиональной автономии, повышение уровня жизни - черты модернизированного общества. Вместе с тем Улам подчеркивает, что либерализация и реформы в России обычно заканчиваются возобновленной волной централизации и притеснения.

Ситуацию в Советском Союзе при Н. С. Хрущеве советолог характеризует как «эрозию тоталитаризма» $[17$, p. 113], используя распространенный в американской советологии термин, встречающийся также в работе Инкельса и Бауэра [18, p. 383-384].

Улам замечает в советском тоталитаризме не только тенденцию к эрозии, но противоположное - нежелание советских лидеров отказываться от тоталитарных средств управления и стремление отклонять любые социальные и политические изменения, угрожающие их власти. Историку удалось увидеть в начале 60-х гг. одно из противоречий тоталитарной системы, повлекшее за собой ее распад в конце 80 -х гг. Это постепенное промышленное развитие страны в сочетании с повышением грамотности населения и, наоборот, сохранение тоталитарного режима, идеологии и методов управления. Советское руководство для удержания власти и сглаживания противоречий убеждало советских граждан, что коммунизм жизнеспособен и энергичен в отличие от устаревших демократических и либеральных идей.

Рассматривает Улам и внешнюю политику постсталинского периода. Его оценки также не выходят за рамки концепции тоталитаризма. Внешняя политика СССР однозначно характеризуется как экспансионистское продолжение российского империализма [17, p. 118]. Подобные характеристики были обусловлены состоянием «холодной войны». Следует заметить, что в основе внешней политики США лежали геополитические и идеологические задачи, которые не всегда решались мирными средствами, например, война США против Вьетнама.

Попытка создания нового определения тоталитаризма в зарубежной историографии была предпринята Г. Спиро в «Энциклопедии социальных наук». Г. Спиро выделил следующие определяющие черты тоталитаризма:

«- приверженность одной, позитивно сформулированной цели (будь то индустриализация, расовое господство и т. д.);

- непредсказуемость и неопределенность, вытекающие из перманентной процедурной флуктуации;

- широкомасштабное использование организованного насилия военными или полувоенными формированиями и секретной полицией;

- усилия по подчинению или ликвидации организаций или ассоциаций, не приверженных режиму;

- стремление достигнуть всеобщего участия населения в общественных организациях, преданных единой цели; 
- универсализация цели в направлении переделки всего человечества по образу и подобию самой тоталитарной системы» [19, p. 108].

Выделение исследователем признака применения насилия было, скорее всего, вызвано событиями в Чехословакии. Трудно согласиться с автором, выделяющим в качестве признака тоталитаризма «непредсказуемость и неопределенность», тем более что далее Г. Спиро пишет о цели «переделки всего человечества».

Таким образом, определение Г. Спиро напоминает логическую конструкцию, подобную синдрому К. Фридриха и 3. Бжезинского. Это определение показало, что изучение тоталитаризма в американской историографии пришло к полному абстрагированию от исторической ситуации, что приводило к своеобразным выводам и дефинициям.

В 60-е гг. был поставлен под сомнение тезис, что фашистский режим в Германии является тоталитарным. Этой проблеме была посвящена статья профессора из Беркли В. Зауэра, ученика известного немецкого историка К. Брахера, «Национал-социализм: тоталитаризм или фашизм?» [20].

Автор считает, что тоталитаризм не давал возможности исследовать в нужной мере историю национал-социалистического режима, но полностью отказаться от этой теории нельзя, так как «современные диктатуры имеют черты тоталитаризма» [20, p. 407].

В качестве недостатка теории В. Зауэр также отмечает нивелирование различий между фашизмом и большевизмом [20, p. 418]. Отвечая на поставленный в заглавии вопрос, автор считает, что «нацизм должен быть определен из нашего понимания природы фашизма как элемента германской истории» [20, р. 424].

Влияние на изменения взглядов на тоталитарную модель в 60-е гг. оказали социальные науки. Например, некоторые социологи, изучавшие Советский Союз в 1960-е гг., группы по интересам и их взаимодействие, казались жизненно важными для динамики общества, а «групповой подход» стал к концу десятилетия объединяющей идеей для ревизионистов теории тоталитаризма.

Социолог Г. Скиллинг был представителем этой позиции. В одной из своих статей он четко отмежевался от тоталитарной модели: «Понятие «тоталитаризма», которое преобладало в анализе коммунизма на Западе, как мне показалось, предотвращает возможность того, чтобы группы по интересам бросали вызов, или оказывали влияние на единственную правящую партию как источник всей власти. Считалось, что уникальность тоталитарной модели лежит в самой тотальности политической власти, исключая по определению любую сферу автономного поведения для групп кроме государства или партии, и более того, предотвращая серьезное влияние с их стороны на процесс принятия решений» [21, р. 435].

Затем Г. Скиллинг выделил «как минимум» восемь групп, которые в определенные периоды времени поддерживают особые интересы: интеллектуалы, юристы, управляющие, преподаватели, представители национальностей, ученые, военные и особая груп- па в самой партии. Подход Г. Скиллинга отрицает исходное условие тоталитарной модели, состоящее в том, что коммунистические системы полностью отличаются от других социальных и политических систем. Если эти группы соревнуются за преобладание на советской политической сцене, не следует ли рассматривать Советский Союз в известной мере как плюралистическое общество? Позиция Г. Скиллинга приводит к абсурду. Д. Хоу позже замечает, что подход «групп по интересам» «рассматривает бюрократов не как марксистский правящий класс, а как образованный средний класс с разнообразными интересами и внутренними конфликтами» [22, р. 399]. Эта позиция Г. Скиллинга еще более приближала Советский Союз к западным обществам.

Под влиянием возросшего интереса в зарубежной историографии к сравнительному анализу различных стран и политических систем в апреле 1966 г. в Университете Чикаго состоялась конференция «Политическая наука на Среднем Западе». Основное внимание на этом форуме было уделено сравнительному анализу в изучении коммунистических систем. Наиболее интересные и дискуссионные выступления были опубликованы в одном из номеров журнала «Славик ревью» («Slavic Review») [23].

Значительное внимание в сделанных докладах было уделено тоталитарной модели, которая использовалась и для сравнения различных политических систем, включая коммунистическую и фашистскую.

С основным докладом «Сравнительное изучение коммунистических политических систем» на конференции выступил известный советолог А. Мейер [23, p. 3-12]. Цель выступления - критика модели тоталитаризма, которая видит сходство в коммунистических системах. А. Мейер же в своей статье (написанной на основе доклада) пытается доказать неповторимость каждого коммунистического государства. Исследователь подчеркивает, что тоталитаризм - это идеальный тип, которому никакая система не соответствует полностью.

Не отказываясь полностью от тоталитарной модели, А. Мейер предложил дополнительную - бюрократическую - модель для изучения коммунистических систем. Эти две модели, по мнению автора, дополняют друг друга, а не противостоят [23, p. 5].

Если тоталитарная модель изучает коммунистическую систему на ограниченном периоде роста, то бюрократическая рассматривает более длительный период накопления власти, а затем функционирования сформировавшейся системы. Однако, как наличие бюрократического аппарата в коммунистической системе способствует выявлению национальных, отличительных черт каждой коммунистической системы, из статьи А. Мейера не ясно. Наоборот, признак бюрократизации делает коммунистические системы схожими вне зависимости от национальной принадлежности.

Безусловно, коммунистический мир гетерогенный. Существуют различия между западными и азиатскими коммунистическими системами (латиноамериканский коммунизм как третий вариант). Думается, что кроме бюрократизма, который выделяет А. Мейер, 
существуют многие другие переменные, отличающие одну коммунистическую систему от другой. Например, различная степень социальной стратификации, различные установленные структуры, различные отношения к власти, различные группы интересов и подкультуры.

В выступлении «Коммунизм и сравнительное изучение» американский политолог Дж. Каутский поддержал А. Мейера в активизации изучения коммунистических систем и сомнений относительно полноценности тоталитаризма $[23$, р. 13, 15]. Однако Дж. Каутский только тезисно говорит о контрасте между коммунистическими и фашистскими системами, между самими коммунистическими системами также. Его точка зрения о том, что концепция тоталитаризма затеняет эти отличия, идет в рамках общей критической тенденции зарубежной историографии тоталитаризма второй половины 60-х гг.

Позицию профессора А. Мейера также поддержали на конференции историки Д. Джекок и Р. Шаркт $[23$, p. 18, 22].

Научный форум, посвященный тоталитаризму и сравнительному изучению коммунистических систем, вызвал резонанс в научных кругах США. В одном из номеров журнала «Славик Ревью» («Slavic Review») вышла статья известного американского социолога П. Холландера «Наблюдения относительно бюрократии, тоталитаризма и сравнительного изучения коммунизма» [24].

В целом П. Холландер разделяет точку зрения А. Мейера о необходимости изучения коммунистических систем через сравнения. Социолог считает, что модель тоталитаризма для такого сравнения устарела, но другой модели он не видит. Поэтому полностью отказаться от тоталитарной модели, считает П. Холландер, преждевременно [24, р. 303].

П. Холландер высоко оценивает применение концепции тоталитаризма в американских исследованиях Советского Союза. Основной недостаток концепции тоталитаризма П. Холландер видит в акцентировании на принуждении, а тем более на терроре. Конечно, такая точка зрения стала возможна только в постсталинский период, когда широкомасштабного террора в Советском Союзе не было. Но различные формы принуждения сохранились, это также выделяет П. Холландер, и на основании этого пишет о невозможности замены тоталитарной модели на бюрократическую модель.

П. Холландер утверждает, что актуальность тоталитарной модели остается при изучении коммунистических режимов даже во второй половине 60-х гг. В качестве достоинств модели социолог выделяет следующие черты:

«1) идеология, основанная на утверждении квазиутопического социального порядка;

2) интенсивность управления;

3) двигатель в виде индустриализации;

4) отсутствие существенного плюрализма;

5) преднамеренно созданная взаимозависимость всех социальных, экономических, политических, административных и культурных учреждений и действий» $[24$, p. 305].

Модель П. Холландера несовершенна, некоторые из вышеперечисленных черт можно встретить не только в коммунистических обществах. Любая модель создает идеальный тип, который в реальности отсутствует. Позитивным для модели П. Холландера является ее приближенность к советской системе 60-х гг.

В модели П. Холландера отсутствует динамизм, выделяются лишь структурные статичные признаки. Этим модель 60-х гг. П. Холландера мало отличается от модели К. Фридриха и 3. Бжезинского 50-х гг. Но если в модели 50-х гг. основной признак - тотальный террор, то у П. Холландера - взаимозависимость всех институтов и действий, отсутствие выбора и свободы действия. То есть модель 60-х гг. фиксирует изменения тоталитарной системы, но не показывает сам процесс эволюции. Вместе с тем это шаг вперед в развитии зарубежной историографии тоталитаризма.

Некоторые зарубежные ученые в рамках критической дискуссии о тоталитаризме ограничились утверждением, что «тоталитарная модель уже дала большую часть того, что могла принести, и что нужны новые модели для изучения коммунистических государств и обществ в постсталинском мире» [19, р. 112]. «По-моему, не существует таких вещей, как правильная или неправильная социологическая модель», - писал социолог А. Инкельс, один из основателей советологии, - «существуют модели более богатые и более бедные» [25, p. 3].

В течение 60-х гг. социологи все чаще начинали чувствовать, что для того, чтобы изучать советскую политическую жизнь, необходимо понять, как общество функционирует через сети подчинения, покровительство и даже через политические и экономические «разногласия». Необходимо подчеркнуть, что исследователи советской политики все больше тяготели к опоре на те же средства анализа, которые используются для изучения других промышленно развитых и «развивающихся» обществ.

К концу 60-х гг. еще одним поводом для критики тоталитарной модели стало мнение ученых, что коммунистические режимы были не статичны, а проходили несколько фаз развития, в ходе которых различные аспекты систем требовали особо детального анализа. Вехой в исследовании коммунистических систем был долгосрочный проект, выполненный при содействии Американского совета научных обществ в конце 1960-х гг. Проект завершился публикацией в 1970 г. коллективной монографии «Перемены в коммунистических системах» [26]. Согласно ее редактору Ч. Джонсону, при изучении «различных коммунистических систем недостаточно использовались новые понятия социологии: изменение, развитие и модернизация. Говоря точнее, тоталитарная модель была неспособна направлять исследование в двух важных вопросах: как изменяются коммунистические системы и почему?» [26, p. 1-2]. 
Выводы дискуссии о тоталитаризме в зарубежной историографии в 60-е гг. заключаются в следующем:

- тоталитарную модель продолжили использовать при изучении диктаторских режимов;

- был подтвержден политизированный характер теории;

- в эти годы основное внимание было сосредоточено на изучении отдельных тоталитарных режимов с их особенностями и различиями.
В заключение необходимо отметить, что под влиянием критического дискурса в зарубежной историографии тоталитаризма в 1970-е гг. создается модернизированная концепция этого феномена. Она используется в основном при изучении фашизма. Основу модернизированной концепции составляет аргумент о «революционности» фашизма, базирующийся на антитезе «движение - режим».

\section{Литература}

1. Мороз Е. В. Феномен тоталитаризма в американской историографии (1930-1980-е годы): автореф. дис. ... д-ра ист. наук. Кемерово, 2006. 50 с.

2. Карпов А. А. Современный тоталитаризм и его разновидности // Ленинградский юридический журнал. 2016. № 1. С. 52-58.

3. Мамедов А. А. О., Оришев А. Б. Тоталитаризм: трактовки прошлого и настоящего // Вестник Московского государственного университета культуры и искусств. 2014. № 2. С. 108-115.

4. Мороз Е. В. Критическое осмысление тоталитаризма в американской политической мысли середины прошлого века (некоторые аспекты проблемы) // Этносоциум и межнациональная культура. 2015. № 2. С. 104-108.

5. Мороз Е. В. Тоталитаризм: интерпретации в зарубежных исследованиях 20-30-х годов XX века (некоторые аспекты проблемы) // Эволюция российского и зарубежного государства и права. К 80-летию кафедры истории государства и права Уральского государственного юридического университета (1936-2016). Сборник научных трудов. Т. ІІ: Эволюция зарубежного государства и права, учений о зарубежном государстве и праве, проблемы теории, философии и методологии права в трудах-поздравлениях коллег / под ред. проф. А. С. Смыкалина. Екатеринбург: Уральский государственный юридический университет, 2016. С. 465-478.

6. Kolko J., Kolko G. The Limits of Power: The World and United States Foreign Policy, 1945-1954. New York: Harper \& Row, 1972. 820 p.

7. Мороз Е. В. Некоторые проблемы эволюции политического учения о тоталитарном государстве // Право и образование. 2010. № 8. С. 68-80.

8. Мороз Е. В. Становление концепции тоталитарного государства в зарубежной общественно-политической мысли 20-30 гг. XX века // Современный мир. Современное образование. Проблемы, тенденции развития, подходы: материалы VI Всероссийской научно-практической конференции. Кемерово, июнь 2012 г. / отв. ред. В. М. Филиппов. Москва: Издательство современного гуманитарного университета, 2012. С. 115-126.

9. Friedrich C. J., Brzezinski Z.K. Totalitarian Dictatorship and Autocracy / 2nd ed., revised by C. J. Friedrich. Cambridge (Mass.): Harvard University Press, 1965. 439 p.

10. Arendt H. The Origins of Totalitarianism. 3d ed. New York: Harcourt Brace \& Company, 1966. 526 p.

11. Arendt H. The Origins of Totalitarianism. New York: Harcourt Brace \& Company, 1973. 576 p.

12. Арон Р. Демократия и тоталитаризм. М.: Текст, 1993. 303 с.

13. Sorokin P. A. Mutual Convergence of the United States and the USSR to the Mixed Sociocultural Type // International Journal of Comparative Sociology. 1960. No. 1. P. 143-176.

14. Миллс Р. Властвующая элита. М.: Издательство иностранной литературы, 1959. 544 с.

15. Мороз Е. В. Критика тоталитарного государства в американской общественно-политической мысли 60-х годов XX века // Социогуманитарный вестник. 2011. № 1. С. 66-73.

16. Gleason A. Totalitarianism. The Inner History of the Cold War. New York, Oxford: Oxford University Press, 1995.307 p.

17. Ulam A. B. The New Face of Soviet Totalitarianism. Cambridge, Mass.: Harvard University Press, 1963.233 p.

18. Inkeles A., Bauer R. A. The Soviet Citizen: Daily Life in a Totalitarian Society. Cambridge, Mass.: Harvard Univ. Pr., 1961. 533 p.

19. Spiro H. J. Totalitarianism // International Encyclopedia of Social Sciences. New York: Macmillan and Free Press, 1968-1976. Vol. 16. P. 106-107.

20. Sauer W. National Socialism: Totalitarianism or Fascism? // The American Historical Review. 1967. December. Vol. LXXIII. No. 2. P. 404-424.

21. Skilling H. G. Interest Group and Communist Politics // World Politics. 1966. April. P. 435-451.

22. Hough J. The «Dark Forces», the Totalitarian Model, and Soviet History // Russian Review. 1987. Vol. 46. Is. 4. October. P. 397-403.

23. Slavic Review. 1967. March. Vol. XXVI. No. 1. P. 1-112.

24. Hollander P. Observations on Bureaucracy, Totalitarianism, and the Comparative Study of Communism // Slavic Review. 1967. June. Vol. XXVI. No. 2. P. 302-307.

25. Inkeles A. Models and Issues in the Analysis of Soviet Society // Survey. 1966. July. P. 3-17.

26. Change in Communist Systems / Ed. Ch. Johnson. Stanford, Calif.: Stanford University Press, 1970. 368 p. 


\title{
CRITICAL DISCOURSE OF TOTALITARIANISM IN FOREIGN HISTORIOGRAPHY OF THE 1960S Elena V.Morozi, @
}

\author{
${ }^{1}$ Plekhanov Russian University of Economics (Kemerovo branch), 39, Kuznetsky Ave., Kemerovo, Russia, 650992 \\ @morozkem@yandex.ru
}

Received 10.10.2017. Accepted 28.11.2017.

\section{Keywords:}

totalitarianism,

historiography, dictatorship, fascism, communism, critique.

\begin{abstract}
The purpose of this article is to analyze the reasons and the substantive content of the critical discourse on totalitarianism developed in foreign historiography of the 1960s. The analysis is based on the fundamental methodological principles of historical study: systemic approach of historicism and scientific objectivity. The research focuses on the works by famous foreign researchers in the area: H. Arendt, P. Sorokin, K. Friedrich, Z. Brzezinski, R. Mills, A. Ulam. The content of these works makes it possible to highlight the main methodological problems of critical discourse. The author criticizes the totalitarian model for its structural and external uniformity and lack of differentiation of totalitarian regimes. Revisionism in foreign historiography of the 1960s contributed to the study of Soviet society on the basis of sociological methodology by highlighting its high social mobility. The critical approach specifies the differences between communist and fascist systems and the peculiarities of individual communist regimes. However, the representatives of the critical approach failed to create a coherent theory compatible to the one offered by the adherents of totalitarianism. The critical discourse of totalitarianism in the 1960s contributed to the formation of a modernized concept of the phenomenon. The final part of the article contains the main conclusions of the discussion. The content and results of this article can be used in foreign historiography courses.
\end{abstract}

For citation: Moroz E. V. Kriticheskii diskurs totalitarizma v zarubezhnoi istoriografii 1960-kh gg. [Critical Discourse of Totalitarianism in Foreign Historiography of the 1960s]. Bulletin of Kemerovo State University, no. 1 (2018): 66-73. DOI:10.21603/2078-8975-2018-1-66-73.

\section{References}

1. Moroz E. V. Fenomen totalitarizma v amerikanskoi istoriografii (1930-1980-e gody). Avtoref. diss. doktora ist. nauk [The phenomenon of totalitarianism in American historiography (1930-1980s years). Dr. hist. Sci. Diss. Abstr.]. Kemerovo, 2006, 50.

2. Karpov A. A. Sovremennyi totalitarizm i ego raznovidnosti [Modern totalitarianism and its variants]. Leningradskii iuridicheskii zhurnal = Leningrad Law Journal, no. 1 (2016): 52-58.

3. Mamedov A. A. O., Orishev A. B. Totalitarizm: traktovki proshlogo i nastoiashchego [Totalitarianism: interpretation past and present]. Vestnik Moskovskogo gosudarstvennogo universiteta kul'tury $i$ iskusstv $=$ Bulletin of the Moscow State University of Culture and Arts, no. 2 (2014): 108-115.

4. Moroz E. V. Kriticheskoe osmyslenie totalitarizma v amerikanskoi politicheskoi mysli serediny proshlogo veka (nekotorye aspekty problemy) [Critical understanding of totalitarianism in American political thought midcentury (some aspects of)]. Etnosotsium i mezhnatsional'naia kul'tura = Ethnosociology and interethnic culture, no. 2 (2015): 104-108.

5. Moroz E. V. Totalitarizm: interpretatsii v zarubezhnykh issledovaniiakh 20-30-kh godov XX veka (nekotorye aspekty problemy) [Totalitarianism: the interpretation of the foreign studies of the 20-30s of XX century (some aspects of)]. Evoliutsiia rossiiskogo i zarubezhnogo gosudarstva i prava. K 80-letiiu kafedry istorii gosudarstva i prava Ural'skogo gosudarstvennogo iuridicheskogo universiteta (1936-2016). Sbornik nauchnykh trudov. T. II: Evoliutsiia zarubezhnogo gosudarstva i prava, uchenii o zarubezhnom gosudarstve i prave, problemy teorii, filosofii $i$ metodologii prava $v$ trudakh-pozdravleniiakh kolleg [Evolution of the Russian and foreign state and law. To the 80th anniversary of the Department of the History of State and Law of the Ural State Law University (19362016). Collection of scientific papers. Vol. II: Evolution of a foreign state and law, doctrines about a foreign state and law, problems of theory, philosophy and methodology of law in works-congratulations of colleagues]. Ed. Smykalin A. S. Ekaterinburg: Ural'skii gosudarstvennyi iuridicheskii universitet, 2016, 465-478.

6. Kolko J., Kolko G. The Limits of Power: The World and United States Foreign Policy, 1945-1954. New York: Harper \& Row, 1972, 820.

7. Moroz E. V. Nekotorye problemy evoliutsii politicheskogo ucheniia o totalitarnom gosudarstve [Some problems of the evolution of political doctrine of the totalitarian state]. Pravo $i$ obrazovanie $=$ Law and Education, no. 8 (2010): 68-80. 
8. Moroz E. V. Stanovlenie kontseptsii totalitarnogo gosudarstva v zarubezhnoi obshchestvenno-politicheskoi mysli 20-30 gg. XX veka [The formation of the concept of the totalitarian state in foreign political thinking in the 20-30 years of the twentieth century]. Sovremennyi mir. Sovremennoe obrazovanie. Problemy, tendentsii razvitiia, podkhody: materialy VI Vserossiiskoi nauchno-prakticheskoi konferentsii. Kemerovo, iiun' 2012 g. [Modern world. Modern education. Problems, development trends, approaches: Proc. VI Russian Sc.-Prac. Conf. (June 2012)]. Ed. Filippov V. M. Moskva: Izdatel'stvo sovremennogo gumanitarnogo universiteta, 2012, 115-126.

9. Friedrich C. J., Brzezinski Z.K. Totalitarian Dictatorship and Autocracy. Revised by Friedrich C. J. Cambridge (Mass.): Harvard University Press, 1965, 439.

10. Arendt H. The Origins of Totalitarianism. New York: Harcourt Brace \& Company, 1966, 526.

11. Arendt H. The Origins of Totalitarianism. New York: Harcourt Brace \& Company, 1973, 576.

12. Aron R. Demokratiia i totalitarizm [Democracy and totalitarianism]. Moscow: Tekst, 1993, 303.

13. Sorokin P. A. Mutual Convergence of the United States and the USSR to the Mixed Sociocultural Type. International Journal of Comparative Sociology, no. 1 (1960): 143-176.

14. Mills R. Vlastvuiushchaia elita [The ruling elite]. Moscow: Izdatel'stvo inostrannoi literatury, $1959,544$.

15. Moroz E. V. Kritika totalitarnogo gosudarstva v amerikanskoi obshchestvenno-politicheskoi mysli 60-kh godov XX veka [Criticism of the totalitarian state in American political thinking in the 60s of XX century]. Sotsiogumanitarnyi vestnik = Social and humanitarian bulletin, no. 1 (2011): 66-73.

16. Gleason A. Totalitarianism. The Inner History of the Cold War. New York, Oxford: Oxford University Press, $1995,307$.

17. Ulam A. B. The New Face of Soviet Totalitarianism. Cambridge, Mass.: Harvard University Press, $1963,233$.

18. Inkeles A., Bauer R. A. The Soviet Citizen: Daily Life in a Totalitarian Society. Cambridge, Mass.: Harvard Univ. Pr., 1961, 533.

19. Spiro H. J. Totalitarianism. International Encyclopedia of Social Sciences. New York: Macmillan and Free Press, vol. 16 (1968-1976): 106-107.

20. Sauer W. National Socialism: Totalitarianism or Fascism? The American Historical Review, December, LXXIII, no. 2 (1967): 404-424.

21. Skilling H. G. Interest Group and Communist Politics. World Politics, April (1966): 435-451.

22. Hough J. The «Dark Forces», the Totalitarian Model, and Soviet History. Russian Review, 46, October (1987): $397-403$.

23. Slavic Review. March, XXVI, no. 1 (1967): 1-112.

24. Hollander P. Observations on Bureaucracy, Totalitarianism, and the Comparative Study of Communism. Slavic Review, June, XXVI, no. 2 (1967): 302-307.

25. Inkeles A. Models and Issues in the Analysis of Soviet Society. Survey, July (1966): 3-17.

26. Change in Communist Systems. Ed. Johnson Ch. Stanford, Calif.: Stanford University Press, $1970,368$. 